\title{
O MOVIMENTO DE BUSCA PELAS TRANSFORMAÇÕES DAS CONCEPÇÕES E PRÁTICAS DE FORMAÇÃO DE PROFESSORES NA UNIVERSIDADE DE SÃO PAULO
}

\author{
Selma Garrido Pimenta \\ Universidade de São Paulo, Faculdade de Educação/FEUSP, Brasil \\ Programa de Pós-Graduação em Educação, Universidade Católica de Santos, Brasil \\ sgpiment@usp.br \\ Maria Isabel de Almeida \\ Universidade de São Paulo, Faculdade de Educação/FEUSP, Brasil \\ Programa de Pós-Graduação em Educação, Universidade Católica de Santos, Brasil \\ mialmei@usp.br
}

\section{RESUMO}

O artigo tem por objetivo discutir o processo de implementação do Programa de Formação de Professores da Universidade de São Paulo (PFPUSP) no período 2006-2020, com destaque para as rupturas e inovações que trouxe ao campo das licenciaturas, bem como a identificação dos desafios e problemas enfrentados no âmbito da Universidade e frente às legislações federais e estadual que têm reconfigurado e, na maioria dos casos, desfigurado a formação dos docentes brasileiros. Com base em pesquisa bibliográfica sobre formação, em documentos da própria Universidade e na legislação, evidencia os esforços voltados para a superação das dicotomias, antigas e arraigadas na área, entre teoria/prática e entre saberes científicos/saberes pedagógicos.

Palavras-chave: Licenciaturas. Institucionalização de políticas. Práxis docente.

\section{THE MOVEMENT OF SEARCH FOR TRANSFORMATION OF CONCEPTIONS AND PRACTICES IN TEACHER EDUCATION AT THE UNIVERSITY OF SÃO PAULO}

\begin{abstract}
The paper aims to discuss the implementation process of the Teacher Training Program at the University of São Paulo (PFPUSP) in the period 2006-2020, highlighting the ruptures and innovations it brought to the undergraduate courses for teacher training, as well as the identification of the challenges and problems faced by the University and the federal and state legislation that have reconfigured and, in most cases, disfigured the training of brazilian teachers. Based on bibliographical research on teacher training, on the University's own documentation and on legislation related to the subject, the efforts aimed at overcoming dichotomies, so old and ingrained in the area, are highlighted, between theory/practice and between scientific knowledge/pedagogical knowledge.
\end{abstract}

Keywords: Teacher training. Institutionalization of policies. Praxis of teaching.

\section{LE MOUVEMENT VERS LES TRANSFORMATIONS DES CONCEPTIONS ET DES PRATIQUES DE FORMATION DE PROFESSEURS A L'UNIVERSITE DE SÃO PAULO}




\section{RESUME}

Cet article a pour but de discuter le processus de mise en place du Programme de Formation de Professeurs de l'Université de São Paulo (PFPUSP) au cours de la période 2006-2020, soulignant les ruptures et les innovations qu'il a introduites dans les cours de formation universitaire des enseignants. Nous exposons par ailleurs les défis et les problèmes qu'il a fallu affronter dans le cadre de l'Université, et face aux législations de la Fédération et des états qui configurent, et souvent défigurent, la formation des enseignants au Brésil. En nous appuyant sur une recherche bibliographique sur la formation des professeurs, sur les documents de l'Université et sur la législation relative au thème, nous présentons les efforts pour dépasser les dichotomies, aussi anciennes que tenaces dans ce domaine, entre théorie et pratique et entre savoirs scientifiques et savoirs pédagogiques.

Mots-clé: Cours de formation universitaire des enseignants. Institutionnalisation des politiques. Práxis de l'enseignement.

\section{EL MOVIMIENTO DE BÚSQUEDA DE TRANSFORMACIONES DE LAS CONCEPCIONES Y PRÁCTICAS DE LA FORMACIÓN DOCENTE EM LA UNIVERSIDAD SÃO PAOLO}

\section{RESUMEN}

El objetivo de este artículo es el de discutir el proceso de implementación del "Programa de Formação de Professores da Universidade de São Paulo" (PFPUSP) en el período 2006-2020, especialmente para las rupturas e innovaciones que trajo al campo de las licenciaturas, así como la identificación de los desafíos y problemas enfrentados en el ámbito de la Universidad y frente a las legislaciones federales y estatales que han reconfigurado y, en la mayor parte de los casos, desfigurado la formación de los docentes brasileños. Con base en pesquisa bibliográfica sobre formación, en la documentación de la propia Universidad y en la legislación referente al tema, se destacan los esfuerzos direccionados a la superación de las dicotomías, tan antiguas y arraigadas en el área, entre teoría/práctica y entre saberes científicos/saberes pedagógicos.

Palabras clave: Licenciaturas. Institucionalización de políticas. Praxis docente.

\section{INTRODUÇÃO}

Neste artigo analisamos o Programa de Formação de Professores da Universidade de São Paulo (PFPUSP) em suas inovações, destacando seus avanços, possibilidades e desafios no movimento de institucionalização na universidade, bem como os embates e confrontos com decisões internas da Universidade e com deliberações do CEE-SP e as resoluções $n^{\circ} 1$ e 2/2002 do CNE.

O PFPUSP foi aprovado pela USP em 2004 e implementado a partir de 2006. Entre 2006 e 2009, período crucial para a implementação do novo projeto, Selma Garrido Pimenta foi Pró-Reitora de Graduação e Maria Isabel de Almeida foi assessora da Pró-Reitoria de 
Graduação da Universidade, estando, portanto, ambas diretamente envolvidas nesse processo de mudanças.

Após 15 anos de ações formativas desenvolvidas à luz das proposições expressas no texto original do Programa de Formação, muitos avanços e alguns entraves foram vivenciados pelos participantes dessa significativa transformação na formação de professores brasileiros. $\mathrm{O}$ esforço analítico aqui empreendido pelas autoras nutre-se da experiência de gestão do órgão implementador dessa nova propositura no seio da Universidade, mas também do acúmulo de conhecimentos advindos da atuação como docentes formadoras de professores, pesquisadoras e produtoras de conhecimentos sobre educação e educadores, participantes de eventos e redes nacionais e internacionais, orientadoras de pesquisas de graduandos e pós-graduandos e da atuação em movimentos sociais, políticos e sindicais vinculados ao campo educacional.

O tema da formação de professores e a relevância social de seu trabalho nos processos de redemocratização do país por meio da educação escolar, tem mobilizado pesquisadores, docentes e estudantes nas universidades brasileiras com vistas a superar as insuficiências do antigo modelo $3+1$. A valorização da escola pública e a ampliação do seu acesso conquistada no país desde finais do século passado, configurou novos cenários e desafios à formação docente. $\mathrm{O}$ estudo teórico da práxis de ensinar permite que a realidade das escolas, seus contextos, seus problemas, assim como as possibilidades de superá-los, sejam colocados no centro de todo o processo formativo dos professores. Atividades de pesquisa e de extensão comparecem nos currículos de modo articulado com o ensino e possibilitando a unidade teoria e prática na práxis formativa dos cursos. Essa perspectiva se faz presente em projetos inovadores em atividade em universidades públicas, muitas vezes confrontando-se à perspectiva das políticas governamentais em curso no país.

É de um Programa de Formação de Professores com essas características que trataremos neste artigo.

\section{MARCAS DA FORMAÇÃO DE PROFESSORES NA UNIVERSIDADE DE SÃO PAULO}

Os cursos de licenciatura para a formação de professores da educação básica estão presentes na Universidade de São Paulo logo após sua fundação em 1934. A Faculdade de Filosofia, criada naquele momento, incorporou a Escola de Professores do Instituto de Educação Caetano de Campos e criou em 1939 o seu curso de Didática (CANDAU, 1987; CACETE, 2014). Esse curso consistia na oferta de seis disciplinas pedagógicas aos bacharéis 
de cursos correspondentes às disciplinas presentes na escola básica, conferindo-lhes também o título de licenciados. Com isso instituiu-se o modelo de formação assentado em três anos de bacharelado acrescido de um ano de formação pedagógica, que ficou conhecido como o regime 3+1 (CASTRO, 1974), que se fez presente em outras instituições e se constituiu no paradigma de formação docente até início do século XXI. Mantendo a mesma estrutura curricular, a formação de professores foi tendo seu lócus reposicionado no interior da USP. Segundo Salces (2020, p. 78), “[...] em 1962 a seção de Pedagogia da então Faculdade de Filosofia, Ciências e Letras da USP foi transformada em Departamento de Educação, que posteriormente se transformou na Faculdade de Educação em 1969”.

Dessa forma, os cursos de licenciatura na USP constituíram-se como complementares à formação profissional nas diversas áreas, uma vez que o bacharelado era pré-requisito para a realização da licenciatura. A formação de professores organizou-se então como fruto da soma de dois campos de saberes - os das áreas específicas e os do campo pedagógico. Essa justaposição fazia com que o estudante apenas passasse a ter contato com a possibilidade da docência enquanto opção profissional já na fase final de seus estudos de bacharelado e sem conseguir compreender a articulação entre esses dois conjuntos de conhecimentos (FÉTIZON, 1984).

Mesmo com esses limites, esse projeto formativo atendia à necessidade de uma escola voltada ainda para parcelas reduzidas das crianças e jovens brasileiros até meados do século XX. Mas na segunda metade desse século o país viveu profundas transformações em sua estrutura econômica, social e urbana, o que trouxe a necessidade de democratizar o acesso à escolaridade pública (FERNANDES, 1962), e esse modelo formativo passou a se mostrar ineficaz. Tornou-se evidente que para cumprir seu papel social, a escola precisava contar com um corpo de professores bem formados e com condições dignas para o exercício do ato de ensinar e aprender. A formação de professores não poderia mais ficar restrita à justaposição de saberes e às dimensões técnicas do processo de ensino.

Desde a década de 1980 as questões relativas à formação dos professores, à organização da escola e à estruturação da profissão docente vem ganhando espaço e relevância nos estudos, pesquisas e nas políticas internacionais. Também no Brasil, esse mesmo movimento foi ganhando lugar e atenção no cenário educacional, na perspectiva de se assegurarem direitos essenciais à cidadania (GUARNIERI, 2005; LIMA, 2004; ALMEIDA; PIMENTA; FUSARI, 2019).

No campo das políticas educacionais é importante destacar a Constituição de 1988 que garantiu os direitos sociais a todos, incluindo a educação. O direito à educação básica está 
assentado na compreensão de que é dever do Estado assegurá-la de forma gratuita a todos, incluindo a ideia, que depois foi complementada pelo Estatuto da Criança e do Adolescente de 1990 e pela Lei de Diretrizes e Bases de 1996, de que a educação básica seria obrigatória, gratuita e de qualidade, da educação infantil ao ensino médio.

No que se refere à formação dos professores, em articulação com os avanços assegurados pela LDB de 1996, ao estabelecer que a formação dos professores deveria ser realizada em cursos de licenciatura plena em nível superior, vieram as diversas Diretrizes Curriculares Nacionais para a Formação de Professores para a Educação Básica (2002), bem como um conjunto de Diretrizes específicas para as distintas áreas de conhecimento presentes na escola. Já as pesquisas e estudos produzidos em programas de pós-graduação, mas não só, caminharam em várias direções: repensaram o modelo formativo conservador, o já citado 3+1; ajudaram a formular outros paradigmas que avançaram na superação da ideia do professor técnico-reprodutor; apontaram a importância da articulação entre a formação inicial e a vivida ao longo da vida profissional; evidenciaram a estreita relação entre condições de trabalho, salário e carreira com os resultados do trabalho docente. Enfim, a produção de conhecimento voltou-se para ressignificar a formação, as condições do exercício docente, o papel dos professores no seu contexto de trabalho, entendendo-o como profissional autônomo, com responsabilidades, direitos e competência técnico-política (NÓVOA, 1992a, 1992b; GIMENO; SACRISTÁN, 1995; CONTRERAS, 2002).

Em meio a essas novas compreensões a respeito do papel social e político dos professores, de sua formação e seu trabalho, foi ganhando espaço a compreensão de que a USP precisaria avançar na reconfiguração de seus cursos de licenciatura. E neste cenário, após intensos debates, a Universidade de São Paulo formulou o seu novo Programa de Formação de Professores (PFPUSP), aprovado em 2004 e implementado a partir de 2006. Para maior compreensão das alterações que o novo programa de formação trouxe aos cursos de licenciatura, é importante apresentar em linhas gerais o contexto de avanço das pesquisas no âmbito educacional e a implementação de reformas políticas na área da formação de professores nacional e internacionalmente.

\section{EMBATES TEÓRICO-POLÍTICOS ACERCA DA FORMAÇÃO DE PROFESSORES}

No mundo ocidental, as últimas décadas do século passado foram palco da formulação de políticas que propiciaram significativas alterações nos sistemas de ensino como a elevação da formação dos professores da escola básica para o nível superior, o investimento na formação 
inicial e contínua, no desenvolvimento das instituições escolares e na elevação do estatuto de profissionalização dos professores, incluindo a reestruturação de quadros de carreira, das condições de trabalho e dos salários.

A compreensão dos professores como profissionais trouxe como decorrência o investimento na valorização, na formação e no desenvolvimento dos seus saberes, fortaleceu a possibilidade de considerá-los como sujeitos e intelectuais, capazes de produzir conhecimento, de participar de decisões e da gestão da escola e dos sistemas. Essas novas premissas conceituais trouxeram perspectivas promissoras para a reinvenção da escola democrática e colocaram-se como contraponto à concepção que compreende os professores e seu papel social no âmbito da racionalidade técnica e às ações que buscam o controle cada vez mais burocrático do trabalho docente, evidenciando uma política ineficaz para assegurar a democratização do ensino e combater a exclusão social no processo de escolarização.

No Brasil, a produção acadêmica na área da educação e da formação de professores foi significativamente impulsionada com a criação, em 1968, dos cursos de pós-graduação. Com o apoio de referenciais fundamentados em teorias críticas, alguns programas de pós-graduação tiveram expressiva contribuição na análise dos problemas educacionais e da escolaridade brasileira, ampliando o caminho para se colocar a educação e a escola em questão. Foi nesse contexto que a formação de professores passou a ser firmemente debatida (SAVIANI, 2009; DINIZ-PEREIRA, 2013). Muitas das proposições resultantes da produção acadêmica, dos movimentos sociais e das experiências de formação de professores realizadas no âmbito de universidades, foram incorporadas por alguns governos democraticamente eleitos na década de 1980. Entendia-se que os professores deveriam ter sólida formação teórica para que pudessem ler, problematizar, analisar, interpretar e propor alternativas aos problemas que o ensino, enquanto prática social, apresentava nas escolas (PIMENTA, 1996). Essa compreensão suscitou novas propostas curriculares e novos modos de desenvolvimento do ensino. Ao mesmo tempo, crescia o entendimento da importância de se elevar ao nível do ensino superior também a formação de professores para as séries iniciais, o que em parte foi incorporado na nova Lei de Diretrizes e Bases da Educação Nacional (LDBEN/96), aprovada em decorrência da Constituição de 1988.

A centralidade colocada nos professores traduziu-se na valorização do seu pensar, do seu sentir, de suas crenças e seus valores como aspectos importantes para se compreender o seu fazer, não apenas de sala de aula, pois os professores não se limitam a executar currículos, senão que também os elaboram, os definem, os reinterpretam. Daí a importância dos estudos voltados para se compreender o exercício da docência, os processos de construção da identidade docente 
e de sua profissionalidade, o desenvolvimento da profissionalização, as condições em que trabalham, o status profissional e sua capacidade de liderança (FREIRE, 1996; ALMEIDA, 1999; PIMENTA, 1996).

A partir dos anos finais do século $\mathrm{XX}$, foram sendo formuladas propostas para a formação de professores fundadas em uma concepção orgânica da educação e da formação de seus profissionais, tendo bem claro o perfil do professor que se pretendia formar para que pudessem desenvolver uma atuação compromissada com a alteração das profundas desigualdades sociais e econômicas marcantes do acesso de amplas parcelas de crianças e jovens à escolarização de qualidade. Como bem o mostram estudos e pesquisas na área, os professores são profissionais essenciais nos processos de mudanças das sociedades (NÓVOA, 1992a, 1992b; MARCELO GARCIA, 1999; PIMENTA, 1996; CONTRERAS, 2002; DINIZPEREIRA, 2013; LÜDKE; BOING, 2004). Se forem deixados à margem das decisões pedagógicas e curriculares, por mais interessantes que possam parecer, elas não se efetivam e não geram efeitos sociais. Por isso, é preciso investir na formação e no desenvolvimento profissional dos professores

Desses avanços nas compreensões teóricas e políticas a respeito do papel sociopolítico dos professores e suas necessidades formativas decorreram reorientações teóricometodológicas para os cursos de licenciatura a parir de três premissas: a estreita vinculação entre os conteúdos científicos e os pedagógicos; o caráter histórico e construtivo da produção do conhecimento; a íntima articulação entre teoria e prática. Portanto, impõe-se considerar que a atividade profissional de todo professor tem uma natureza pedagógica, isto é, vincula-se a objetivos educativos de formação humana e a processos metodológicos e organizacionais de transmissão, apropriação e produção de saberes e modos de ação. O trabalho docente está impregnado de intencionalidade, pois visa a formação humana por meio de conteúdos e habilidades de pensamento e ação, implicando escolhas, valores, compromissos éticos.

Além disso, é no âmbito do processo educativo que mais íntima se afirma a relação entre a teoria e a prática. Na sua essência, a educação é uma prática intrinsecamente intencionalizada pela teoria. Decorre dessa condição, a atribuição de um lugar central ao estágio, no processo da formação do professor. Entendendo que o estágio é constituinte de todas as disciplinas, percorrendo o processo formativo desde seu início, os cursos de licenciatura precisam contemplar várias modalidades de articulação direta com as escolas públicas e demais instâncias nas quais os professores atuarão, apresentando formas de estudo, análise e problematização dos saberes nelas praticados. O estágio também pode ser realizado como espaço de projetos interdisciplinares e de pesquisa, ampliando a compreensão e o conhecimento da realidade 
profissional de ensinar (ALMEIDA; PIMENTA, 2014). As experiências docentes dos alunos que já atuam no magistério, como também daqueles que participam da formação continuada, devem ser valorizadas como referências importantes para serem objeto de discussão e reflexão.

\section{O PROGRAMA DE FORMAÇÃO DE PROFESSORES DA UNIVERSIDADE DE SÃO PAULO}

Com o desafio de superar a fragmentação na formação de professores para a Educação Básica, tradicionalmente configurada pela soma do bacharelado nas áreas específicas e a licenciatura na área pedagógica, a USP, após longo processo de discussões iniciado em meados dos anos 1980, elaborou o Programa de Formação de Professores (PFPUSP, 2004), formulado por comissão composta de representantes de todas as Unidades envolvidas com a formação de professores e coordenado pela Pró-Reitoria de Graduação.

A característica principal e inovadora do PFPUSP é que a formação de professores se configura como um projeto político-pedagógico único, integrado, definido e desenvolvido conjuntamente pelas unidades envolvidas na oferta dos conhecimentos específicos ${ }^{1}$ e da área pedagógica ${ }^{2}$. Para maior compreensão, seguem os principais pontos estruturantes do Projeto.

Estabeleceu-se então que a finalidade maior dos cursos de licenciatura seria a formação inicial de professores para a educação básica com capacidade científica e profissional, politicamente motivados a lidar com a diversidade da população atendida hoje em nossas escolas. Para tanto, defende-se que os professores tenham domínio dos conteúdos da sua área específica e da área pedagógica como requisitos para que compreendam a complexidade do mundo da escola de modo a atender as expectativas daqueles que hoje a frequentam, contribuindo assim para a transformação da realidade brasileira. Ele é orientado por sete princípios:

1. A formação de professores na USP exige empenho permanente de suas diversas unidades, pois trata-se do estabelecimento de uma política de formação que requer esforço permanente de avaliação; acompanhamento e reformulação.

2. A docência e a vida da escola são focos do programa, pois parte-se da compreensão de que a docência se realiza dentro de um complexo contexto social e institucional.

\footnotetext{
${ }^{1}$ São assegurados por Institutos, Escolas e Faculdades presentes nos vários campi da Universidade de São Paulo.

2 A USP possui uma Faculdade de Educação, localizada no campus da Capital e Departamentos de Educação, nos campi de Piracicaba, São Carlos e Ribeirão Preto.
} 
3. A formação de professores deve ter na escola pública seu principal foco de interesse de estudo, acompanhamento e melhoria da ação docente, pois a articulação entre os cursos de Licenciatura e as escolas públicas se constitui em elemento importante para a formação destes, uma vez que nela está a maioria da população excluída de direitos.

4. $\underline{O}$ projeto de formação deve assegurar a indissociabilidade entre ensino, pesquisa e extensão, pois só assim os cursos de Licenciatura podem se constituir em uma etapa da formação profissional, base do permanente e necessário processo de formação continuada.

5. A formação do professor dar-se-á ao longo de todo o processo de formação nos cursos de graduação, rompendo-se com a ideia da justaposição.

6. As estruturas curriculares dos cursos de Licenciatura devem ser flexíveis e oferecerem uma pluralidade de caminhos aos licenciandos, o que pode concretizar-se pela oferta de disciplinas compartilhadas por mais de um curso, além de projetos de formação e de intervenção multidisciplinares e interunidades.

7. A instituiç̧ão escolar e sua proposta pedagógica devem ser o eixo norteador das diferentes modalidades de estágio supervisionado, propiciando ao futuro professor o conhecimento da instituição escolar como um todo.

A estrutura curricular mínima está organizada em quatro blocos de disciplinas e atividades, que se articulam com os estágios supervisionados, a prática como componente curricular, as atividades teórico-práticas de aprofundamento e os conteúdos curriculares de natureza científico-cultural:

Bloco I - Formação específica - disciplinas e atividades diretamente relacionadas aos conhecimentos da área específica.

Bloco II - Iniciação à Licenciatura - 2 disciplinas e atividades introdutórias à formação do professor da Educação Básica: Introdução aos Estudos da Educação e Disciplina de intersecção da área específica com a educação básica.

Bloco III - Fundamentos teóricos e práticos da Educação - 3 disciplinas e atividades relacionadas à formação pedagógica em geral: Didática, Psicologia e POEB (Política e Organização da Educação Básica). São de responsabilidade da Faculdade e/ou Departamentos de Educação e associadas ao estágio supervisionado.

Bloco IV - Fundamentos metodológicos do ensino - 2 disciplinas e atividades relacionadas ao ensino das áreas específicas: Metodologia do Ensino de... São de responsabilidade da Faculdade e/ou Departamentos de Educação e estão associadas ao estágio supervisionado. 
Os componentes comuns são fixados por legislação nacional totalizando o mínimo de 2.800 horas $^{3}$ de curso, a serem desenvolvidos em, no mínimo, quatro anos:

1. conteúdos curriculares de natureza científico cultural, com duração mínima de 1.800 horas (referem-se aos conteúdos específicos de cada área do conhecimento);

2. estágio curricular supervisionado, com duração mínima de 400 horas, ligadas a trabalho de campo realizado em contato direto com as unidades escolares dos sistemas de ensino e a serem compartilhadas entre as unidades de origem $(100$ h $)$ e a Faculdade/Departamentos de Educação (300 h).

3. prática como componente curricular, com duração mínima de 400 horas (entendidas como atividades ligadas à formação profissional voltadas para a compreensão das múltiplas dimensões das práticas educativas);

4. atividades teórico-práticas de aprofundamento, com duração mínima de 200 horas (atividades formativas em sentido amplo, devendo propiciar a ampliação do universo cultural e acadêmico do licenciando).

A concepção do PFPUSP previu uma estrutura organizativa dos cursos de formação de professores com a intenção de criar condições favoráveis ao rompimento com as práticas formativas segmentadas e as culturas institucionais indutoras da tradição. Assim, propôs “[...] formas de organização institucional que tenham como objetivo viabilizar projetos articuladores das licenciaturas que sejam capazes de contemplar [...] a diversidade de perspectivas e necessidades formativas" (PFPUSP, 2004, p.8). Propôs então a criação de uma Comissão Interunidades de Licenciatura - CIL, apoiada nas Comissões Coordenadoras de Curso - CoCs.

As CoCs já existiam desde 1990 nos cursos da USP que fossem ministrados por mais de uma unidade e tradicionalmente cuidavam do acompanhamento do currículo e das atividades existentes, com a colaboração de representantes dos demais cursos. O PFPUSP agregou-lhes a responsabilidade de "[...] proposição de novos arranjos curriculares, de atividades formativas [...], de criar mecanismos institucionais capazes de viabilizar propostas de integração interdisciplinares e interunidades e projetos de estágio supervisionado" (PFPUSP, 2004, p. 910). Com caráter consultivo, as CoCs passaram então a ter o papel de propor ações para o aperfeiçoamento constante das licenciaturas às instâncias deliberativas locais ou gerais da Universidade.

À CIL coube ser "[...] o centro articulador da política de formação de professores da USP” (PFPUSP, 2004, p. 12), com papel de assessorar o Conselho de Graduação. Composta

\footnotetext{
${ }^{3}$ Essa carga horária, definida pela Resolução CNE 02/2002, foi alterada pela Resolução CNE n. 02/2015 para 3.200 horas.
}

Rev. Iberoam. Patrim. Histórico-Educativo, Campinas (SP), v. 7, p. 1-28, e021013, 2021. 
por representantes das CoCs de todas as Unidades participantes dos 29 cursos de licenciatura e por representantes estudantis, recebeu as atribuições de analisar e contribuir com o aperfeiçoamento das propostas curriculares advindas das CoCs; analisar as propostas de disciplinas e atividades à luz da diretrizes formativas das licenciaturas; estimular projetos integrados entre docentes, disciplinas, departamentos ou institutos em atividades formativas e estágio supervisionado; realizar encontros ou eventos sobre formação e atuação docente para o público da USP e das escolas parceiras; divulgar aos profissionais das escolas parceiras as possibilidades de participar em formações e pesquisas desenvolvidas pela Universidade.

Para a efetivação do PFPUSP, todas as unidades com cursos de licenciatura foram contempladas com novos docentes dedicados centralmente ao Programa. Também foram contratados educadores com o papel de intermediar a relação entre a Universidade e as escolascampo de estágio.

Com esse novo Programa de Formação de Professores, a USP reafirmou seu compromisso social com a educação básica e buscou formular uma proposta inovadora para a formação dos professores de maneira a atender a novas exigências sociais e em conformidade com as determinações legais, o que significa formar profissionais capazes e motivados para lidar com a diversidade da população atendida hoje pela escola básica.

\section{RUPTURAS NO PARADIGMA DE FORMAÇÃO DE PROFESSORES - INOVAÇÕES DO PFPUSP}

Os docentes formadores de professores da Universidade de São Paulo, mesmo na fase em que as proposições formativas eram marcadas pelos limites da justaposição de conjuntos de conhecimentos estanques, estiveram conectados e foram partícipes dos questionamentos teóricos nacionais e internacionais sobre o tema, atuaram junto aos movimentos sociais e acompanharam ativamente as ações políticas que foram reposicionando tanto as compreensões sobre o papel social dos professores como as bases teórico-metodológicas de sua formação. Esse engajamento foi fundamental para a formulação de um programa de formação capaz de romper com os limites que historicamente marcaram a formação de professores no país.

Uma primeira marca dessa ruptura foi superar a fragmentação presente no percurso formativo, expressa na 'fórmula' $3+1$, responsável por sobrepor dois blocos de conhecimentos de campos distintos e tratados desarticuladamente, o que instituiu o caráter de complementação que a licenciatura agregava à formação profissional. O PFPUSP abriu caminho para alterar esse modelo ao propor um projeto integrado de formação de professores, de responsabilidade das

Rev. Iberoam. Patrim. Histórico-Educativo, Campinas (SP), v. 7, p. 1-28, e021013, 2021. 
unidades do bacharelado e da licenciatura, o que resultou na compreensão de que a formação docente se faria em um continuиm intrinsecamente articulado entre as disciplinas do campo específico de conhecimento do futuro professor e outras voltadas especificamente à educação, ao ensino e ao exercício da docência. Essa tecedura se faz presente ao longo de todo o percurso formativo e sua arquitetura foi possível graças à atuação da CIL enquanto centro político de gestão e articulação do PFPUSP.

Essa proposta integradora teve importante suporte no compromisso coletivo com a mudança do paradigma orientador da formação firmado por todas as instâncias da Universidade e pelo conjunto de formadores presentes na vida acadêmica do licenciando. Expressou-se com isso a compreensão de que o futuro professor precisa não só dominar de modo verticalizado os conhecimentos de sua área de especialização, mas também compreender a problemática da escola contemporânea, bem como dominar teórica e metodologicamente a dimensão pedagógica do seu fazer. Esse compromisso sedimentou o caminho para acabar com a concorrência entre os distintos conjuntos de conhecimentos expressa na falsa questão "onde se forma o professor - na área dos estudos específicos ou nos estudos pedagógicos?"

A efetivação desse compromisso coletivo sedimentou-se em cada Unidade com a elaboração de um projeto próprio para o seu curso de licenciatura em estreita consonância com o PFPUSP, superando mais um aspecto da desarticulação até então existente. Essa elaboração foi realizada pelas CoCs, com a colaboração de representantes da Faculdade ou Departamentos de Educação, e foi amplamente discutido e balizado pelas diretrizes gerais do novo programa no interior da CIL. Essa articulação mostrou-se importante para assegurar o alcance dos princípios e objetivos da nova proposta.

Outra ruptura foi assegurar que as questões do universo escolar estejam presentes em todo o percurso de formação, desde o início dos cursos de ingresso e não mais apenas na sua etapa final, quando então eram realizados os estágios. Essa articulação entre universidade e escola, presente desde o início da graduação, permitiu maior aproximação dos licenciandos com seu futuro local de trabalho e abriu um leque de temáticas a serem aprofundadas e pesquisadas a partir de sua área de conhecimento, que não se separa do universo do ensino no momento da atuação profissional. Essa aproximação efetivou-se por meio de rearranjo curricular ou da criação de disciplinas com caráter introdutório ao universo escolar e também pela realização de 100 horas de estágio supervisionado na Unidade de ingresso do licenciando, o que permitiu evidenciar a pertinência dos conteúdos estudados nos campos de conhecimentos específicos ao mundo da escola. As novas possibilidades de se pensar sobre a escola e sobre as questões referentes ao ensino trouxeram repercussões positivas para o restante do percurso formativo, 
especialmente às 300 horas de estágio supervisionado na Faculdade ou Departamento de Educação.

O PFPUSP consolidou uma compreensão do estágio supervisionado como elemento integrador da formação do futuro professor, que é parte um projeto de trabalho da Unidade, a ser realizado em escolas conveniadas e entendidas como co-formadoras dos licenciandos. Essa compreensão rompe com a ideia de que os estagiários busquem as escolas para o cumprimento de uma exigência apenas legal para a sua formação, uma vez que o estágio se coloca como espaço para investigar, problematizar e propor respostas à realidade escolar, abrindo espaço para a contrapartida da Universidade às escolas parceiras por meio de ações de formação continuada aos seus professores.

Para dar conta de tamanha reorganização na formação dos professores foram contratados novos docentes e educadores destinados especialmente aos cursos de licenciatura. Assumir que docentes dedicados à formação de futuros professores precisam ter um perfil voltado aos estudos e pesquisas acerca do lugar social da escola e dos processos de ensinar e aprender foi um grande passo da USP para iniciar o rompimento da cultura institucional que tradicionalmente tem secundarizado o lugar e a importância da formação de professores dentre suas ações. Como aprofundamento dessa ruptura, também foram contratados educadores, com o requisito de terem experiência como docente na escola básica. Eles são funcionários técnicos com a função de articular as relações entre Universidade e escolas-campo por meio dos projetos de estágio; também atuam na organização do trabalho nos laboratórios didático-pedagógicos em apoio às atividades de estágio, e favorecem a realização de ações de formação continuada para os professores das escolas públicas parceiras.

\section{A CRIAÇÃO DE DISCIPLINAS COMO PARTE dA RECONFIGURAÇÃo DA FORMAÇÃO DE PROFESSORES}

À época da implementação do PFPUSP pela Pró-Reitoria de Graduação (PRG) na gestão 2006-2009, a USP contava com cerca de 5.500 cargos de professores efetivos para seus 240 cursos de graduação, oferecidos em 42 Unidades (Faculdades ou Institutos) de Ensino, Pesquisa, Extensão, em seus sete campi situados na Capital de São Paulo e nos municípios de Ribeirão Preto, São Carlos, Piracicaba, Bauru, Pirassununga e Lorena. Dentre as Unidades, 18 ofertavam cursos de licenciatura, além do bacharelado, sendo 12 na capital, com oferta de 19 cursos de licenciatura, e 06 no interior, com oferta de 10 licenciaturas, totalizando 29 cursos de licenciatura na Universidade. 
O principal desafio da PRG para assegurar a implementação do novo Programa foi a conquista de 90 (noventa) novos cargos docentes ${ }^{4}$, apontados pelas 18 unidades que ofereciam os 29 cursos de licenciaturas como condição para a efetivação das mudanças pretendidas. Aprovados no Conselho Universitário, os cargos foram sendo preenchidos por meio de concursos públicos realizados ao longo do período 2006 - 2009.

Uma vez conseguida a aprovação dos claros, outras questões se colocaram: Quais disciplinas as unidades iriam propor? Quais concepções teóricas sobre docência e formação de professores estariam na base das propostas? Como conceberiam o ensino, atividade precípua do docente?

Dos 90 cargos concedidos, as Unidades realizaram concursos para 86 disciplinas criadas pelas CoCs em articulação com a CIL e aprovadas pelo Conselho de Graduação. Destas, 65 foram alocadas no Bloco II e 21 foram alocadas no Bloco IV.

O levantamento dos títulos das disciplinas foi realizado pela Profa. Noeli Prestes Padilha (USP/Ribeirão Preto), tendo por fontes seus arquivos pessoais; Relatórios CIL - 2007, 2008, 2009; Editais publicados no Diário Oficial do Estado de São Paulo - 2006 a 2009; registros no Sistema Júpiter (USP); Projetos Pedagógicos dos Cursos de Licenciatura; e Plataforma CNPq Lattes.

Disciplinas do Bloco II: das 65 disciplinas alocadas nesse Bloco, 21 claros foram para disciplinas já existentes na Faculdade de Educação, que não serão aqui analisadas por não se constituírem em inovação curricular. Os demais 44 claros foram destinados às unidades dos campi do interior e à Escola de Artes, Ciências e Humanidades - EACH.

Uma análise dos títulos ${ }^{5}$ criados para as disciplinas desses 44 claros, evidencia alguns avanços e aderências ao proposto no PFPUSP, como destacamos a seguir.

Organizados em 5 agrupamentos, os títulos e temas pertinentes aos editais de concurso para docente ajudam a evidenciar algumas possibilidades, mas também alguns limites do movimento de busca pelas transformações nas concepções e práticas de formação de professores na USP.

Num primeiro grupo estão títulos e temas disciplinares escolhidos pelas Unidades de Humanas e de Exatas para preenchimento de 17 claros docentes. Essas proposições articulam

\footnotetext{
${ }^{4}$ É importante lembrar que criar cargos novos é um processo difícil, altamente complexo porque envolve ampliação do orçamento da Universidade. Assim, a concessão dos cargos solicitados exclusivamente para as Licenciaturas, evidenciou o apoio da então Reitora Profa. Dra. Suely Vilela ao novo Programa.

${ }^{5}$ Para uma compreensão ampliada de possíveis transformações ou permanências no âmbito das unidades que oferecem licenciaturas seria necessária a análise das Ementas, Programas e Referências Bibliográficas das disciplinas criadas, bem como dos Editais dos concursos e dos Perfis dos candidatos aprovados. Esse estudo está ainda por ser feito.
} 
temáticas das áreas específicas de conhecimento e a área da Educação, sugerindo um olhar mais ampliado e um diálogo possível e necessário entre suas especificidades. Também é possível identificar que elas não se restringem a nomenclaturas tradicionais, mas expressam maior abrangência e riqueza temática, evidenciando novas compreensões e contribuições das Unidades à formação docente, o que é coerente com o proposito maior do PFPUSP - articular os conhecimentos da área específica e os educacionais. Num segundo grupo estão14 disciplinas cujos títulos se referem diretamente ao ensino dos conhecimentos específicos em diálogo com os conhecimentos pedagógicos. Em um último grupo de 09 disciplinas, os títulos se referem a instrumentação, tecnologias e experimentos de ensino na área de Exatas.

Esse movimento mostra a efetiva inserção da formação de professores nos bacharelados da Universidade. No entanto, contrariando as finalidades da criação dos novos claros, nesse Bloco II do Programa, encontramos em uma Unidade 04 disciplinas que em seus títulos não evidenciaram relação com formação de professores.

Disciplinas do Bloco IV: esse bloco concentra as disciplinas de Metodologia do Ensino de... e Estágios Supervisionados, destinadas a articular os saberes pedagógicos e os conteúdos específicos; foram criados 21 novos claros. A FE recebeu 13 claros; os demais 08 foram para as unidades do interior e a EACH.

A análise do conjunto de disciplinas/claros para ambos os blocos evidencia o processo inicial de mudanças na cultura institucional sobre a formação de professores na Universidade ${ }^{6}$. No entanto, sabemos que um projeto, ainda que coletivamente formulado como o PFPUSP, não é suficiente para alterar substantivamente as concepções e práticas existentes. Criar novas disciplinas voltadas à formação de professores no âmbito dos bacharelados foi um passo importante, mas outras ações institucionais foram organizadas para levar aos bacharelados e aos docentes ingressantes os fundamentos teórico, epistemológico e político do campo da formação de professores.

No período de nossa gestão (2006-2009), criamos e implementamos dois Programas com finalidades e objetivos próprios, que deram suporte ao esforço de implantação do PFPUSP. Um foi o Programa de Pedagogia Universitária, voltado à formação pedagógica dos professores da Universidade e à valorização do trabalho docente nos cursos de graduação (PIMENTA; ALMEIDA, 2011). O outro foi o Programa Ensinar com Pesquisa e Pesquisar o Ensinar (PIMENTA, 2021), que apoiou com bolsas e recursos financeiros o desenvolvimento

\footnotetext{
${ }^{6}$ Outras análises sobre o PFPUSP podem ser consultadas em PIPITONE; ZUFFI e RIVAS (2010); e ZUFFI, 2016, docentes que estiveram à frente dos trabalhos da CIL.
} 
de 4.425 projetos de pesquisa sobre o ensino de graduação na USP, cujos resultados foram apresentados por docentes e estudantes de graduação em eventos nacionais e internacionais. Esses dois Programas contribuíram para inserir a temática da formação de professores em todos os cursos de bacharelado e licenciatura da Universidade.

\section{EMBATES ATUAIS ENFRENTADOS PELO PFPUSP}

Ao longo dos 15 anos de existência do PFPUSP muitas dificuldades foram enfrentadas e superadas, quer seja no âmbito das Unidades ou mesmo da Universidade. Porém, nos últimos 5 anos os obstáculos - e até mesmo os ataques - mudaram de patamar e partiram de duas direções. Num primeiro plano houve ações políticas externas, quer seja no plano estadual ou federal, que enfraqueceram e minaram as estruturas da formação de professores no país. Mas também ocorreram ações internas à Universidade que atingiram o Projeto em sua estrutura organizativa e articuladora das licenciaturas. É delas que falaremos a seguir.

\section{O PFPUSP e as DCNs CNE n. 01 e 02/2002 - contradições teóricas e políticas}

Tendo por parâmetros legais as Resoluções n. 01 e 02 do Conselho Nacional de Educação (BRASIL/MEC/CNE 2002) que definem as diretrizes curriculares nacionais para a formação de professores em todo o país, a USP, no uso de sua autonomia conforme o artigo 207 da Constituição Federal de 1988, reiterada pela LDBEN/1996, propôs inovações nos fundamentos, princípios e formas institucionais em seu PFPUSP que avançam em relação a esse documento legal.

Essa legislação estabeleceu as competências como núcleo da formação docente o que configura o exercício profissional como técnico/prático. Essa compreensão guarda relação com a concepção tecnicista dos anos 1970 que reduz o trabalho docente à transmissão de conhecimentos. Sua formação consistiria, assim, no domínio dos conhecimentos das áreas específicas e das habilidades pedagógico-instrumentais para ensinar, mantendo o modelo $3+1$.

O conceito de competências (ALMEIDA, 2009) substitui o de conhecimentos teóricos, saberes e qualificação próprios ao exercício profissional docente. Não se trata de simples troca de palavras, mas de profunda alteração nos sentidos e significados da formação e da profissão docente uma vez que expropria dos professores sua condição de sujeitos dos conhecimentos teóricos/práticos que lhes permite compreender, analisar, propor e criar novas formas de exercer sua profissão, a partir da análise das situações nas quais o ensinar ocorre. 
Embora o PFPUSP expresse em seus princípios uma compreensão diversa dessa Diretriz, pode-se indagar: terá sido essa concepção tecnicista a adotada por Unidades da USP ao definirem suas novas disciplinas? Em parte, talvez, se considerarmos que essa concepção praticista redutora da formação e do trabalho do professor era (e talvez ainda o seja) fortemente enraizada na sociedade em geral, incluindo as universidades.

Nesse sentido, é oportuno o Relatório elaborado pela CIL (2016), que apresenta suas análises sobre o PFPUSP em andamento. Por meio de questionários respondidos pelos Coordenadores de seus 29 cursos de Licenciaturas e dos depoimentos coletados no Encontro de Avaliação do PFPUSP (2015), constatou inicialmente “[...] o reconhecimento de que o programa tem sido fundamental para a maior valorização dos profissionais que atuam ou aturarão na Educação Básica e dos formadores de professores em nível superior" (Relatório CIL, 2016, p. 9). No entanto, a análise dos dados evidenciou também a coexistência na Universidade de duas concepções opostas: o professor como técnico-prático e o professor como intelectual crítico reflexivo (PIMENTA; GHEDIN, 2002). Sobre a primeira, afirma a CIL com apoio em Guimarães (2006), que essa:

[...] concepção resulta numa formação focada em um "agente institucional de ensino" [7], que deve ser o responsável pela aplicação de apostilas ou manuais prontos, produzidos por agentes externos à realidade escolar, e atender a um mercado de ações educacionais para estados e municípios que os consomem; os saberes evocados nessa formação são praticamente ausentes ou reduzidos à dimensão da prática, sem espaço para teorias e reflexões, o que o envolve em um estatuto profissional precário, com contratos por tempo determinado e, portanto, o torna descartável dentro dos sistemas educacionais. (Relatório CIL, 2016, p. 9)

Sobre a segunda, o relatório da CIL considera que essa concepção:

[...] privilegia a formação do professor com status de pesquisador de sua práxis, considerando $\mathrm{o}$ ato docente situado nos contextos escolares, promovendo um amplo e sólido conhecimento dos contextos social e político que envolvem o ensino e das realidades onde vivem seus alunos; leva em conta (...) conhecimentos da educação e da pedagogia em conexão com a práxis pedagógica docente, para analisar, compreender e criar procedimentos de ensino que assegurem as aprendizagens, de forma a se tornarem participantes ativos na reinvenção das práticas e das escolas. Para tanto, deve promover sólida formação teórica que lhes permita compreender as realidades em que atua/atuará e propor coletivamente caminhos para assegurar as aprendizagens e o desenvolvimento de todos os alunos, em compromisso com a superação

\footnotetext{
${ }^{7}$ Expressão cunhada em pesquisa realizada pela Fundação Carlos Chagas, publicada no artigo de SILVA; ALMEIDA; GATTI, 2016, p. 297). Os referentes definidos pelas autoras - Conhecimento Profissional do Professor; Prática Profissional e Engajamento Profissional - foram utilizados nas deliberações do CEE-SP e mantidos no artigo $4^{\circ}$ da Res. CNE/CP n ${ }^{\circ}$ 02/2019 (Nota das autoras).
}

Rev. Iberoam. Patrim. Histórico-Educativo, Campinas (SP), v. 7, p. 1-28, e021013, 2021. 
das desigualdades educacionais. Com isso, o estatuto profissional em que se insere demanda um quadro de carreira, ingresso por concurso, a garantia de condições de permanência e desenvolvimento profissional. (Relatório CIL, 2016, p. 9)

Essa concepção se sustenta teórica, epistemológica e politicamente nos avanços de pesquisas nacionais e internacionais sobre educação e formação de professores nos contextos das demandas sociais de desigualdades provocadas pelo neoliberalismo do século XXI sobre formação e desenvolvimento profissional docente.

Ciente de que mudanças de cultura e concepções não podem ser garantidas somente com a aprovação de um novo programa, na sequência do processo de implementação, a CIL seguiu desempenhando seu papel decisivo para assegurar o Programa em seu caráter coletivo de integração entre os cursos de licenciaturas, assessorando e promovendo a formação contínua na área de seus membros coordenadores das CoCs, realizando análises e ajustes com vistas a superar os problemas decorrentes da implementação de um projeto institucional dessa magnitude. Em seus encontros sistemáticos a participação ativa e interessada de todos os envolvidos - docentes, estudantes, e funcionários - foi se ampliando. A parceria com as escolas públicas com vistas à realização das atividades de estágios vem sendo também ampliada com a institucionalização dos cargos técnico-administrativos de Educadores. O protagonismo destes tem sido altamente relevante para consolidar os projetos de estágios nas Unidades, com destaque para a Faculdade de Educação que se responsabiliza pelo maior número de horas nesse componente curricular, em sua maioria realizados com as escolas públicas.

Os esforços até então empreendidos expressam a vitalidade do movimento de reformulação das Licenciaturas da USP, que se coloca sabiamente em relação às legislações externas entendendo que:

[...] a lei não $f a z$ a realidade, embora se proponha a discipliná-la. Ainda que os teóricos da ciência do Direito relutem às vezes em admiti-lo, leis jurídicas não são iguais a leis científicas. Determinam, não explicam; sancionam, não solucionam; derivam de doutrinas, não de teorias (SILVA JÚNIOR, 2015, p. 41).

E sem as teorias não se constrói uma nova realidade. A teoria, sabemos, não altera a realidade; ao contrário, a reflexão sobre a realidade é condição para a ação transformadora. Por sua vez, a ação refletida transforma o pensar, a teoria. Ou, no dizer de Konder (1992, p. 115): "É a ação que, para se aprofundar de maneira mais consequente, precisa da reflexão, do autoquestionamento, da teoria; e é a teoria que remete à ação, que enfrenta o desafio de verificar seus acertos e desacertos, cotejando-os com a prática". 
A CIL se configura, de fato, como espaço de permanentes reflexões teóricas a partir das práticas. Nesse processo contribui para os enfrentamentos externos contrários que a USP e as demais estaduais paulistas vinham sofrendo, como veremos no item a seguir.

\section{A Deliberação CEE-SP 2011/2012 - ataques à autonomia das universidades} estaduais paulistas e ao Projeto da USP

A legislação educacional brasileira confere aos conselhos estaduais de educação a possibilidade de complementar as diretrizes nacionais, por meio de deliberações próprias. A eles compete também credenciar e recredenciar os cursos oferecidos nas universidades de seus estados. Assim, sobre as universidades pertencentes ao sistema estadual paulista (USP, UNICAMP e UNESP), recaem as deliberações do CEE-SP.

Conforme Zan (2019, p. 7), “[ [...] em entrevista concedida à Revista Veja (Páginas Amarelas) em fevereiro de 2008, a professora Maria Helena Guimarães de Castro $^{8}$, então Secretária de Educação Básica do Estado de São Paulo, afirmava que o baixo desempenho dos estudantes do Estado nas avaliações de larga escala se devia à má formação dos professores, especialmente os egressos das universidades públicas em seus cursos de licenciaturas e clama por uma formação mais técnica dos profissionais da educação".

Esse posicionamento da então secretária resultou na Deliberação 111/2012, do CEESP, que Fixa Diretrizes Curriculares Complementares (à Resolução CNE 1 e 2/2004, então em vigor) para a Formação de Docentes para a Educação Básica nos Cursos de Graduação de Pedagogia, Normal Superior e Licenciaturas, oferecidos pelos estabelecimentos de ensino superior vinculados ao sistema estadual.

Essa Deliberação do CEE-SP suscitou forte reação de docentes e pesquisadores das universidades estaduais paulistas, especialmente porque “[...] o texto se contrapõe ao princípio do professor como um profissional que demanda uma formação multidisciplinar e ampliada para o exercício do magistério e pelo caráter prescritivo do documento" (ZAN, 2019, p. 5), e evidencia o perfil dos conselheiros ligados aos setores privatistas da educação:

Levantamento realizado pelo Observatório da Ação Educativa em 2012, mostrava que $59 \%$ dos membros do CEE/SP pertenciam ao setor privado (sendo sócios, representantes ou consultores do setor) e 3\% eram compostos por supervisores de ensino. Além disso, 30\% deles estavam no mandato por

\footnotetext{
${ }^{8}$ A Profa. Maria Helena Guimarães de Castro assumiu diversos cargos nos âmbitos nacional e estadual, dentre os quais a Secretaria Executiva do MEC (2016 a 2018) e a presidência do CNE a partir de 2020.
} 
mais de 9 anos e alguns com quase duas décadas de representação (ZAN, 2019, p. 4).

Profundas diferenças e oposições podem ser identificadas entre as Diretrizes do CEE paulista e o PFPUSP. Editadas em 2012, quando o Programa estava em andamento há pelo menos seis anos, os termos dessa deliberação do CEE 111/2012 aprofundam o tecnicismo instrumental presente na resolução nacional de 2004. O PFPUSP a ela se contrapõe em defesa dos avanços teóricos, epistemológicos e políticos do campo da formação de professores nas licenciaturas da USP.

Os ataques às universidades estaduais paulistas, explicitados em 2008 pela então Secretária de Educação, não foram simples e casuísticos destemperos de uma gestora pública, mas de profissional organicamente articulada aos conselheiros que definiram a deliberação de 2012 (e as subsequentes 126/2014 e 154/2017 ${ }^{9}$ ). De certa forma, já anunciavam os ataques diretos à autonomia das universidades a elas outorgada pela CF 1988.

Nos anos que se seguiram à Deliberação CEE-SP 111/2012, esse Conselho criou comissões compostas por seus membros e/ou convidados, com a finalidade de examinar se os cursos das universidades estaduais paulistas estavam ajustados às determinações legais com vistas à obtenção de seu credenciamento/recredenciamento. No Relatório CIL de 2015 está evidenciado o movimento inicial de análise dessa Deliberação que coordenou junto às CoCs, acatando algumas propostas para maior explicitação de conteúdos, ementas e atividades de estágio.

No entanto, além dos ajustes exigidos e extrapolando suas competências, o CEE passou a impor como condição de recredenciamento dos cursos de licenciaturas a retirada dos programas de várias disciplinas de conteúdos que consideravam "muito teóricos" e referenciais bibliográficos que consideravam "ideológicos". Por mediação da CIL, os cursos de Licenciaturas denunciaram esse movimento aos órgãos competentes da Universidade e reagiram ao ataque explícito à autonomia universitária e à liberdade de cátedra, reação essa construída e sustentada junto às demais Universidades públicas paulistas, como segue:

Exercendo seu papel no campo da pesquisa, experimentação, análise e crítica, bem como de produção de conhecimento, as três Universidades Estaduais

\footnotetext{
${ }^{9}$ Análises elaborada por Cardoso et al (2021) sobre as deliberações do CEE-SP indicam a existência de estreita similaridade textual e política com as orientações das políticas do governo Bolsonaro para a área da educação e formação de professores. Os autores demonstram que as orientações do Conselho Estadual paulista se configuram, metaforicamente, como "o ovo da serpente" dos projetos que vêm sendo praticados pelo governo federal. Exemplo disso são os esboços para novas diretrizes para as licenciaturas em Pedagogia, em elaboração pelo CNE, que reedita a ideia das competências técnicas como fundamento para um exercício prático da docência.
} 
Paulistas, em suas várias instâncias decisórias, não se furtaram a apontar a obsolescência das proposições bibliográficas e conteúdos disciplinares propostos por aquele Conselho. As universidades também indicaram que as restrições a áreas de conhecimento e o direcionamento de autores e orientações teóricas, impostas pelo $\mathrm{CEE}$, não apenas ferem a autonomia universitária, como representam um retrocesso, pois impedem o desenvolvimento de áreas de conhecimento, campos teóricos e da crítica, já consolidados. (Relatório CIL, 2015, p. 12-13)

O movimento de reforma das diretrizes prosseguiu no âmbito nacional e estadual paulista, reforçando a compreensão de que as políticas educacionais continuam ao sabor dos governos em vigor, distanciando-se de ações de Estado, especialmente na política de formação de professores.

Assim, em substituição às diretrizes de 2002 formuladas no governo Fernando Henrique Cardoso (por um CNE vinculado majoritariamente aos interesses privatistas na educação), o CNE publicou a Resolução n. 2/2015, que institui Diretrizes Curriculares Nacionais para a Formação Inicial e Continuada dos Profissionais do Magistério da Educação Básica, em consonância com as metas estabelecidas no Plano Nacional de Educação 2014 2024.

Promulgada no governo Dilma Roussef, diferentemente da anterior, a Diretriz 2/2015 resultou de amplo debate nacional com representantes das entidades que congregam pesquisadores da área, alguns dos quais ocupavam assento no $\mathrm{CNE}$, com associações acadêmico-científicas e sindicatos de professores.

Diversas análises, dentre as quais a realizada por Pimenta e Lima (2017), evidenciam as superações teóricas e políticas da Resolução 2/2015, em relação às concepções tecnicistas/pragmatistas da anterior e das deliberações do CEE-SP. Assim, se aproximam dos pressupostos e princípios do PFPUSP.

No entanto, com a clara intenção de manter seu autoritarismo sobre as universidades estaduais paulistas, o CEE-SP reedita no período entre 2012 e 2015 sua deliberação complementar de 2012 e edita as complementares 132/2015 e 154/2017, contrapondo-se às concepções da Resolução CNE 2/2015, e aos avanços de Programas e experiências inovadores que USP, Unicamp e Unesp vinham praticando em seus cursos de licenciaturas.

\section{Embates e tensionamentos internos à Universidade de São Paulo}

Para alcançar a transformação pretendida na formação de professores na Universidade de São Paulo e avançar alguns passos na mudança da cultura e das concepções sobre esse tema,

Rev. Iberoam. Patrim. Histórico-Educativo, Campinas (SP), v. 7, p. 1-28, e021013, 2021. 
a CIL desempenhou papel fundamental enquanto espaço integrador dos cursos de licenciatura. No âmbito de suas ações desenvolveu-se a formação contínua dos coordenadores das CoCs; incrementaram-se as parcerias com as escolas públicas com vistas à realização das atividades de estágios; realizaram-se análises das proposições curriculares, das novas disciplinas, dos ajustes e dos problemas que inevitavelmente decorrem do processo de implementação de um projeto institucional da magnitude do PFPUSP.

As atas e relatórios de suas atividades coletivas são expressão dos ganhos alcançados na constituição de uma colegialidade acadêmica poucas vezes exercitada. Funcionando como estrutura articulada e articuladora das instituições e sujeitos envolvidos com a formação de professores, a CIL foi ajudando a reconfigurar o lugar das licenciaturas na cultura e nas práticas de gestão da Universidade. No entanto, esses deslocamentos foram causando incômodo e provocando reações nos altos escalões da governança universitária, pois cada equipe gestora é orientada por visões muitas vezes dissonantes, fragilizando ou mesmo interrompendo algumas políticas institucionais.

A gestão reitoral 2014-2017 acabou por colocar obstáculos às demandas encaminhadas pela CIL referentes à infraestrutura dos cursos; contratação de docentes e educadores para cobrir novas exigências legais feitas às licenciaturas; revisão das estruturas curriculares para efeito de credenciamento/recredenciamento dos cursos. Outro ponto significativo de tensão foi a resistência da CIL às pressões do CEE-SP contra os cursos de licenciatura - num aberto desrespeito à autonomia universitária - ao mesmo tempo em que os representantes da Reitoria manifestaram concordância com os procedimentos e ações do Conselho.

Todos esses fatores elevaram o tensionamento das relações entre CIL e Pró-Reitoria de Graduação, pois os embates e questionamentos foram sendo nutridos pela crescente coesão construída entre os participantes da Comissão e pela articulação tecida entre CIL e os representantes da Unicamp e Unesp contra as incursões do CEE-SP.

Na verdade, o que se evidencia com esses embates é o incômodo que o empoderamento dos cursos de formação de professores foi ganhando nos primeiros 8 anos de implementação do PFPUSP. A solução encontrada pela PRG (2014 - 2017) foi deixar de agendar as reuniões da CIL a partir de 2015 como forma de esvaziar sua ação política, medida que causou reação de seus integrantes e levou a tentativas de manter reuniões autoconvocadas. Mas a burocracia da Universidade se fez mais forte e essas inciativas foram minguando. Evidenciou-se então o propósito reitoral de quebrar a articulação estrutural dos cursos de licenciatura e o revigoramento das ações individualizadas pelas distintas CoCs. 
Após três anos de desarticulação da CIL, a PRG instituiu em 2019 um novo Regimento da Graduação e criou uma Câmara de Licenciatura e Apoio Pedagógico - CLAP - como mais uma comissão assessora. Composta por 7 membros partícipes do Conselho de Graduação, sendo 2 de cada grande área de conhecimento - Biológicas, Exatas e Humanas - e um representante discente, essa nova instância está muito distante da representatividade então existente na CIL, quando todas as licenciaturas se faziam presentes. Com a ausência de um espaço articulador das licenciaturas, também deixou de existir a interlocução entre parceiros e as trocas de experiências, o que vinha se mostrando como altamente favorecedor aos encaminhamentos da formação de professores.

Os 6 docentes participantes da CLAP são presidentes das Comissões de Graduação de suas unidades e porta-vozes do conjunto de assuntos relativos à graduação junto ao Conselho de Graduação (CoG). Participar de uma Câmara com foco nas licenciaturas transcende em muito suas amplas responsabilidades, na medida em que passam a acumular também as questões atinentes às especificidades desses cursos, com o agravante de que eles nem sempre têm sua vida acadêmica ligada à formação de professores. Ainda há a considerar a possibilidade de maior controle sobre as decisões e encaminhamentos da CLAP, que está sob o comando direto e próximo do pró-reitor de graduação.

Esta maneira das duas últimas gestões reitorais conduzirem os rumos da formação de professores na Universidade de São Paulo evidencia a vontade política de exercer o controle sobre a implementação do PFPUSP dentro da lógica de contenção de gastos e de concordância com diretrizes político-educacionais que têm buscado desarticular propostas independentes de formação de professores compromissadas com as transformações educacionais e sociais voltadas à maioria da população brasileira.

\section{Finalizando...}

Dentre os avanços que configuram inovações na transformação da formação de professores na USP se destaca o seu caráter de projeto integrado e integrador das Unidades, o que permite superar as dicotomias, tão antigas e arraigadas na área, entre teoria/prática e entre saberes científicos/saberes pedagógicos como já sinalizamos anteriormente. Destacamos, ainda, a valorização e o apoio institucional às pesquisas realizadas por docentes e estudantes sobre a práxis de ensino na graduação e a ampliação dos espaços de formação/aproximação nas unidades/faculdades ou departamentos de educação na gestão inicial da implementação do Programa, buscando o entrelaçamento desses saberes e instâncias por meio desse projeto institucional que se desdobra em diversos projetos locais de construção da profissionalidade docente. Destacamos também a criação de claros docentes enraizando as novas disciplinas nos 
bacharelados. Os Estágios Supervisionados, superando a dicotomia tradicionalmente existente entre as Faculdades/Institutos específicos e a Faculdade de Educação, vêm sendo realizados em projetos conjuntos nos espaços dos cursos em todas as Unidades. Apoiados institucionalmente com a criação de cargos técnicos ocupados por educadores contratados, a tão desejada e necessária aproximação/articulação com as escolas dos sistemas públicos de ensino têm se tornado uma realidade. Esses são ganhos e avanços inestimáveis que evidenciam o enraizamento da nova licenciatura na cultura simbólica e institucional da Universidade de São Paulo, enquanto "[...] expressão de sentido comum compartilhado por um conjunto de atores que agem de acordo com valores e regras coletivamente partilhados" (ARRUDA, 2019, p. 2), definidores de objetivos publicamente reconhecidos. Alterações profundas e retrocessos, no entanto, poderão ocorrer, mas, certamente, serão dificultados.

Os embates e confrontos teórico-políticos evidenciados neste texto, permanecem e se prolongam no atual contexto das idas e voltas das políticas institucionais e das políticas educacionais em curso no país - BNCC; BNC-F, BNCC Ensino Médio e outras -, cuja efetivação se assenta no forte protagonismo dos Conselhos de Educação. Por isso, nos parece oportuno e relevante destacar o perfil de seus conselheiros como apontado por Evangelista et al (2019): em sua maioria são representantes dos conglomerados econômicos, que detêm cerca de $80 \%$ das matrículas de licenciaturas no país. A esses grupos interessa oferecer cursos baratos que formem professores práticos, sem teoria, sem pesquisa e outras frivolidades, como dizem. Mas a formação barateada e aligeirada também interessa aos segmentos dominantes da nossa sociedade, pois contribui para manter a ideologia hegemônica, voltada à manutenção do status $q u o$, o que é facilitado pela oferta de uma escola esvaziada, empobrecida, desfigurada.

\section{REFERÊNCIAS}

ALMEIDA, M. I. O sindicato como instância formadora dos professores: novas contribuições ao desenvolvimento profissional. 1999. 225 f. Tese (Doutorado em Educação) Faculdade de Educação, Universidade de São Paulo, São Paulo.

ALMEIDA, M. I. Professores e competência: revelando a qualidade do trabalho docente. In: ARANTES, V. A. (org.) Educação e competências. São Paulo, Summus, 2009, p. 77-122.

ALMEIDA, M. I.; PIMENTA, S. G.; (Orgs.). Estágios supervisionados na formação docente. São Paulo: Cortez Editora, 2014, 156 p.

ALMEIDA, M. I.; PIMENTA, S. G.; FUSARI, J. C. Socialização, profissionalização e trabalho de professores iniciantes. Educar em Revista, n. 78., v.35, 2019, p. 187-206. Disponível em: 
https://www.scielo.br/j/er/a/RVf6F5s9DNwybqcZsVvdX5D/?lang=pt\&format=pdf. Acesso em $15 / 07 / 2021$.

ARRUDA, M. A. do N. Reflexões sobre cultura institucional e as universidades. In: Jornal da USP, 05/08/2019. Disponível em: https://jornal.usp.br/?p=263375. Acesso em: 09/08/2021 BRASIL. MEC/CNE. Resolução no 01, de 18 de fevereiro de 2002. Institui Diretrizes Curriculares Nacionais para a Formação de Professores da Educação Básica, em nível superior, curso de licenciatura, de graduação plena. Brasília, 2002. Disponível em: http://portal.mec.gov.br/cne/arquivos/pdf/rcp01 02.pdf. Acesso em 15/07/2021.

BRASIL. MEC/CNE. Resolução no 02 , de 19 de fevereiro de 2002. Institui a duração e a carga horária dos cursos de licenciatura, de graduação plena, de formação de professores da Educação Básica em nível superior.

Disponível em: http://portal.mec.gov.br/cne/arquivos/pdf/CP022002.pdf. Acesso em $15 / 07 / 2021$.

BRASIL. MEC/CNE. Resolução no 02, de $1^{\circ}$ de julho de 2015. Define as Diretrizes Curriculares Nacionais para a formação inicial em nível superior (cursos de licenciatura, cursos de formação pedagógica para graduados e cursos de segunda licenciatura) e para a formação continuada. Disponível em:

$<$ http://portal.mec.gov.br/docman/agosto-2017-pdf/70431-res-cne-cp-002-03072015pdf/file>. Acesso em 15/07/2021.

CACETE, Núria H. Breve história do ensino superior brasileiro e da formação de professores para a escola secundária. Educação e Pesquisa, São Paulo, v. 40, n. 4, p. 1061-1076, out./dez. 2014. Disponível em: https://doi.org/10.1590/S1517-97022014005000011. Acesso em 10/07/2021.

CANDAU, Vera M. F. Novos rumos da licenciatura no Brasil. Brasília: INEP; Rio de Janeiro, PUC/RJ, 1987, 93 p.

CARDOSO, N.; FARIAS. I. S; MENDONÇA, S. G. L. O “ovo da serpente” na formação docente: as diretrizes paulistas. Práxis Educacional. Vitória da Conquista, v. 17, n.46, p. 126, Jul./Set. 2021. Disponível em: https://doi.org/10.22481/praxisedu.v17i46.8913. Acesso em 03/07/2021.

CASTRO, A. D. A licenciatura no Brasil. Revista de História. São Paulo, v. 50, n. 100, p. 627-652, out./dez, 1974. Disponível em:

http://www.revistas.usp.br/revhistoria/article/view/132649/128733. Acesso em 17/07/2021.

CONTRERAS, J. D. A autonomia de professores. Trad. Sandra T. Valenzuela. São Paulo: Cortez, 2002, $296 \mathrm{p}$.

DINIZ-PEREIRA, J. E. A construção do campo da pesquisa sobre formação de professores. Revista da FAEEBA, Salvador, v. 22, n. 40, p. 145-154. jul./dez. 2013. Disponível em: https://www.revistas.uneb.br/index.php/faeeba/article/view/7445/4808. Acesso em: 15/07/2021.

EVANGELISTA, O.; FIERA, L.; TITTON, M. Diretrizes para formação docente é aprovada na calada do dia: mais mercado. Jornal socialista e independente: Universidade à Esquerda, 
2019. Disponível em: https://universidadeaesquerda.com.br/debate-diretrizes-para-formacaodocente-e-aprovada-na-calada-do-dia-mais-mercado/. Acesso em 24/02/2021.

FERNANDES, F. Formação de profissionais e especialistas nas faculdades de filosofia. Revista Brasileira de Estudos Pedagógicos, Rio de Janeiro, v. 37, n. 85, p. 227-233, 1962.

FÉTIZON, B. A. M. A propósito da formação de professores. Revista da Faculdade de Educação, São Paulo, 8(2): 165-174, jul./dez. 1982.

FREIRE, P. Pedagogia da autonomia: saberes necessários à prática educativa. $1^{\mathrm{a}}$ ed. Rio de Janeiro: Paz e Terra, 1996, 135 pp.

GIMENO SACRISTÁN, J. Consciência e acção sobre a prática como libertação profissional dos professores. In: NÓVOA, A. (org.). Profissão professor. 2 ed. Porto Ed., 1995. p. 63-92.

GUARNIERI, M. R. O início da carreira docente: pistas para o estudo do trabalho do professor. In: GUARNIERI, M. R. (Org.) Aprendendo a ensinar: o caminho nada suave da docência. 2 ed. Campinas: Autores Associados, 2005, p. 5-25.

GUIMARÃES, V. Socialização Profissional e Profissionalização Docente. In GUIMARÃES (org). Formar para o mercado ou para a autonomia? $O$ papel da Universidade. Campinas. Papirus. 2006, p. 129-152.

KONDER, L. O futuro da filosofia da práxis: o pensamento de Marx no século XXI. $1^{\mathrm{a}}$. Ed. Rio de Janeiro: Paz e Terra, 1992, 140 p.

LIMA, E. F. A construção do início da docência: reflexões a partir de pesquisas brasileiras. Revista do Centro de Educação, v. 29, n. 2, 2004.

LÜDKE, M.; BOING, L. A. Caminhos da profissão e da profissionalidade docentes. Educação e Sociedade, Campinas, v. 25, n. 89, p. 1159-1180, set./dez, 2004.

MARCELO GARCIA, C. Formación del professorado para el cambio educativo. $2^{\circ}$ edição. Barcelona: EUB, 1995, 526 p.

NÓVOA, A. (Coord.). Os professores e a sua formação. Lisboa: Dom Quixote, 1992a, 158 p.

NÓVOA, A. (Org..). Vidas de professores. Porto: Porto Editora, 1992b, 214 p.

PROGRAMA de Formação de Professores da Universidade de São Paulo - PFPUSP. PróReitoria de Graduação - USP. Disponível em: http://www4.fe.usp.br/wpcontent/uploads/programa-de-formacao-de-professores/programa-de-formacao-deprofessores.pdf. Acesso em 10/07/2021.

PIMENTA, S. G. Formação de professores: identidade e saberes da docência. In: Educação e Pesquisa (USP), São Paulo, v. 22, n.2, 1996, p. 72-89.

PIMENTA, S. G.; GHEDIN, E. Professor Reflexivo no Brasil: gênese e crítica do conceito. $1^{\text {a }}$ edição. São Paulo. Cortez. 2002, 261 p.

PIMENTA, S.; ALMEIDA, M. I. A construção da Pedagogia Universitária no âmbito da Universidade de São Paulo. In: PIMENTA, S.; ALMEIDA, M. I. (orgs). Pedagogia 
Universitária: caminhos para a formação de professores. $1^{a}$. São Paulo: Cortez, 2011, p.19-44.

PIMENTA, S. G.; LIMA, M. S. L. Estágio e Docência. 8a. edição. São Paulo: Cortez, 2017, $310 \mathrm{p}$.

PIMENTA, S. G. Relatório Final de Pesquisa - A pesquisa na graduação: Ensinando com pesquisa e pesquisando o ensinar. Bolsa de Produtividade em Pesquisa (2006 - 2021). CNPq. 2021. 30 p.

PIPITONE, M. A. P.; ZUFFI, E. M.; RIVAS, N. P. Um programa de formação de professores: o caso da Universidade de São Paulo. Revista Brasileira de Estudos Pedagógicos, Brasília, 2010, v. 91, n. 227, p. 144-160, jan./abr.

PRÓ-REITORIA DE GRADUAÇÃO - Programa de Formação de Professores da Universidade de São Paulo - PFPUSP, 2004. Disponível em: http://www4.fe.usp.br/wpcontent/uploads/programa-de-formacao-de-professores/programa-de-formacao-deprofessores.pdf. Acesso em 15/06/2021.

RELATÓRIO DE GESTÃO 2006/2009. Pró-Reitoria de Graduação, Universidade de São Paulo, nov. 2009. Disponível em: < http://www.prg.usp.br/wp-content/uploads/rel_selma.pdf.

RELATÓRIO - COMISSÃO INTERUNIDADES DAS LICENCIATURAS, PRG, USP. (inédito). 27 pp. Fevereiro de 2016.

RELATÓRIO - COMISSÃO INTERUNIDADES DAS LICENCIATURAS, PRG, USP. (inédito). 27 pp. Fevereiro de 2016.

RESOLUÇÃO CoG no 7825, de 25/09/2019, disponível em http://www.leginf.usp.br/?resolucao=resolucao-cog-no-7825-de-25-setembro-2019. Acesso em 23/07/2021.

SALCES, C. D. Ser professor formador de professores na Educação Superior privada contemporânea. 2020. 221 f. Tese (Doutorado em Educação) - Faculdade de Educação, Universidade de São Paulo, São Paulo.

SÃO PAULO. CEE. Deliberação CEE no 111, de 01/02/2012 Fixa Diretrizes Curriculares Complementares para a Formação de Docentes para a Educação Básica nos Cursos de Graduação de Pedagogia, Normal Superior e Licenciaturas, oferecidos pelos estabelecimentos de ensino superior vinculados ao sistema estadual. Disponível em https://www.fe.unicamp.br/eventos/seminariofe/2013/GT1-PropostaAlteracaoDelib-CEE1112012. Acesso em 22 set. 2019.

SÃO PAULO. CEE. Deliberação no 126, de 14 de junho de 2014 - Altera dispositivos da Deliberação 111/2012. Disponível em: http://www.ceesp.sp.gov.br/ceesp/textos/2014/651-06Delib-126-14-Indic-127-14.pdf. Acesso em 14/07/2021.

SÃO PAULO. CEE. Deliberação no 132, de 09 de abril de 2015 - Altera dispositivos da Deliberação 111/2012. Disponível em: http://www.ceesp.sp.gov.br/ceesp/textos/2015/65106-Delib-132-15-Indc-132-15.pdf>. Acesso em 14/07/2021. 
SÃO PAULO. CEE. Deliberação no 154, de 31 de maio de 2015 - Publicada no DOE/SP em 07/06/2017. Dispõe sobre alteração da Deliberação CEE nº111/2012. Disponível em: https://normativasconselhos.mec.gov.br/normativa/pdf/CEE-SP_PAR_635_794_2000.pdf>. Acesso em 14/07/2021.

SAVIANI, D. Formação de professores: aspectos históricos e teóricos do problema no contexto brasileiro. Revista Brasileira de Educação, v. 14 n. 40 jan./abr. 2009. Disponível em:

https://www.scielo.br/j/rbedu/a/45rkkPghMMjMv3DBX3mTBHm/?format=pdf\&lang=pt. Acesso em 08/07/2021.

SILVA JÚNIOR, C. A. Das instituições às organizações escolares: políticas comprometidas, culturas omitidas e memórias esquecidas. In: Para uma teoria da escola pública no Brasil. SILVA JÚNIOR, C. A. (org). Marília: M3T Edições, 2015. p.39/64.

SILVA, V. G.; ALMEIDA, P. C. A.; GATTI, B. A. Referentes e critérios para a ação docente. Cadernos de Pesquisa, vol. 46, n.160, p. 286-311. abr/jun. 2016. Disponível em: http://publicacoes.fcc.org.br/index.php/cp/article/view/3415 Acesso em 12/07/2021.

ZAN, D. D. P. Formação de professores em disputa: a experiência da Unicamp. Formação em movimento, Rio de Janeiro, v.1, n.2, p.314-328, jul./dez. 2019. Disponível em: http://costalima.ufrrj.br/index.php/FORMOV/article/view/524. Acesso em 12/07/2021.

ZUFFI, E. M. O programa de formação de professores e a gestão dos cursos de licenciatura na Universidade de São Paulo. In Políticas para a formação de professores da educação básica: modelos em disputa. In: PENITENTE, L. A. A.; MENDONÇA, S. G. L. (orgs). Marília: Cultura Universitária. 2016. p. 57/72. 